\title{
An overview of seismic testing needs in Europe: towards a new advanced experimental facility
}

\author{
Francesco Marazzi • Ioannis Politopoulos • \\ Alberto Pavese
}

Received: 5 July 2010 / Accepted: 16 September 2010 / Published online: 9 October 2010

(C) Springer Science+Business Media B.V. 2010

\begin{abstract}
This paper presents a synthesis of the activities carried out in the framework of the European project EFAST (design study of a European Facility for Advanced Seismic Testing) to determine the general characteristics of a new European world-class facility for earthquake testing of structures. To this end the demands for the necessary testing to support the modern seismic engineering research have been investigated and compared to the actual capabilities of European laboratories. The outcome is the determination of performance objectives and requirements in the gross. On the basis of the needs assessment carried out during the first phase of the project and taking into account the technological advances in both experimental techniques and equipment (hardware and software) for seismic testing, a modern facility for experimental seismic research should be composed, mainly, of a high performance shaking tables array and a large reaction structure where both traditional (pseudo-static/dynamic) and innovative testing techniques (e.g. real time hybrid testing) can be applied and combined. A tentative layout of the facility is also proposed and issues related to the best utilization of such a laboratory are discussed.
\end{abstract}

Keywords Seismic $\cdot$ Testing methods $\cdot$ Testing facilities $\cdot$ Experimental needs

\footnotetext{
F. Marazzi (凶)

European Commission, Joint Research Centre, Institute for the Protection and Security of the Citizen, European Laboratory for Structural Assessment (ELSA), via Enrico Fermi 2749, TP 480, 21027 Ispra, VA, Italy

e-mail: francesco.marazzi@jrc.ec.europa.eu

I. Politopoulos

Commissariat à l'Énergie Atomique, DEN/DANS/DM2S/SEMT, Bâtiment 603, CEA Saclay, 91191 Gif-sur-Yvette Cedex, France

e-mail: ioannis.politopoulos@cea.fr

A. Pavese

European Centre for Training and Research in Earthquake Engineering (Eucentre), via Ferrata 1, 27100 Pavia, Italy

e-mail: alberto.pavese@eucentre.it
} 


\section{Introduction}

Seismic events of the recent past have proved that European and neighbouring countries, especially those in the Mediterranean area, are exposed to a high seismic risk (University of Grenoble 2005, http://www.sesame-fp5.obs.ujf-grenoble.fr/index.htm). Surprisingly the number of victims and the overall economic losses are important compared to industrialized countries like Japan and the United States which are often faced with higher levels of shaking. This fact can be explained by considering the higher population density, and the fact that the high number of damaged buildings is due to the large number of monuments or ancient masonry buildings often vulnerable to earthquake loading.

It is readily apparent that, in developed countries, although the numbers of victims of major earthquakes is tending to drop, the costs of the consequences are constantly rising (UNDP 2006). These costs due to significant damage and widespread disorganization in the area, are constantly rising. Considering damage to plants, loss of data and drops in productivity, are extremely costly. A recent example is the social and economic impact of the L'Aquila (Italy) earthquake in April 2009. It is therefore indispensable for Europe to intensify research and development in the field of earthquake engineering (Wenzel 2007).

In the last decades considerable advances have been achieved in the Earthquake Engineering (EE) field. The research results have contributed to the preparation of modern design codes, to the identification of several problems in the existing structures and to innovative solutions for the structural assessment. Despite this huge amount of improvements there are still several open questions. Some examples are listed below. Predictive models have frequently been calibrated on experimental results obtained from scaled structures. Several innovative technologies for building constructions are entering the market and require careful evaluations to verify the level of safety. The experimental validation of the behavior of large infrastructures (bridges or retaining walls) often requires multi-support excitation. Further insight into soil structure interaction requires testing of heavy models, etc. Available data and future results need to be organized into databases, in order to disseminate them, optimize their use, and provide relevant information for risk oriented approaches. Research to address these issues requires a large amount of analytical and experimental studies.

Moreover, a look at the international EE landscape reveals that, outside Europe, there are several high performance seismic testing facilities either already operating or under construction. There is a trend, mainly in USA and Asia (China, Japan, Korea) towards facilities with an array of shaking tables which increases operating ease and enable multi-support excitations. The objective is to test structures at the largest possible scale in order to avoid scaling effects. Tables 1 and 2 present the characteristics of some of the major shaking table and reaction wall, respectively, laboratories in the world. It is observed that European shaking table laboratories have considerably lower capacities than that of their counterparts outside Europe. This means that, unavoidably, if the situation does not change, Europe will cumulate a considerable lag in experimental earthquake EE and in EE in general, with respect to the USA and Asian countries. In addition, it is worth noting that there is an emergence of advanced experimental techniques, such as real-time substructuring and advanced measurement techniques that are being explored in the most innovative laboratories. This is an important point since the new experimental methods, based on the substructuring technique, have the advantage of reducing the specimen size allowing a better use of the available testing machines' capacity.

For all the aforementioned reasons a new platform for seismic testing in Europe is not just useful but necessary. A new high performance testing facility will enable studying a 
Table 1 Major shaking tables facilities in the word (Taucer and Franchioni 2005)

\section{Major shaking tables in USA}

The NEES Equipment Site at the University of Nevada at Reno (http://www.nees.unr.edu/) is a biaxial, multipleshake-table facility (with three identical biaxial shake-tables) that is suitable for conducting research on long, spatially distributed, structural and geotechnical systems. The facility is also capable of testing conventional structural and non-structural systems by using the tables in large-table-mode operating them as a single unit. Each table is $4.3 \times 4.5 \mathrm{~m}$ and has a maximum payload of 45 tons. The maximum stroke is $\pm 300 \mathrm{~mm}$, the maximum velocity is $\pm 1270 \mathrm{~mm} / \mathrm{s}$ and the maximum acceleration is $1 \mathrm{~g}$ in the frequency range of $0-50 \mathrm{~Hz}$. The NEES Equipment Site at the State University of New York at Buffalo (http://www.nees.buffalo.edu/) consists of a set of two high-performance, six degrees-of-freedom shake tables, which can be rapidly repositioned from directly adjacent to one another to positions up to $30 \mathrm{~m}$ apart (centre to centre). Together, the tables can host specimens of up to 100 tons and as long as $35 \mathrm{~m}$, and subject them to fully in-phase or totally uncorrelated dynamic excitations. Each table is $3.6 \times 3.6 \mathrm{~m}$, but they can be extended to $7 \times 7 \mathrm{~m}$. They have a maximum payload of 50 tons each. The maximum stroke is $\pm 150 \mathrm{~mm}$ ( $\pm 75 \mathrm{~mm}$ in vertical direction), the maximum velocity is $\pm 1250 \mathrm{~mm} / \mathrm{s}$ ( $\pm 500 \mathrm{~mm} / \mathrm{s}$ in vertical direction) and the maximum acceleration is $1.15 \mathrm{~g}$ in the frequency range of $0-50 \mathrm{~Hz}$.

The NEES Equipment Site at the University of California at San Diego (http://www.nees.ucsd.edu/) counts with the world's first outdoor shake table and the largest shake table in the USA. It is able to test structures weighing up to 2200 tons and as tall as $30 \mathrm{~m}$. The facility consists of a $7.6 \mathrm{~m}$ wide by $12.2 \mathrm{~m}$ long platform operated as a single degree of freedom (DOF) system with the capability of upgrading to 6-DOF. The maximum stroke is $\pm 750 \mathrm{~mm}$, the maximum velocity is $\pm 1800 \mathrm{~mm} / \mathrm{s}$ and the maximum acceleration is $1 \mathrm{~g}$ in the frequency range of $0-20 \mathrm{~Hz}$.

\section{Major shaking tables in Japan}

The largest Japanese earthquake-testing facility E-Defense (http://www.bosai.go.jp/hyogo/ehyogo/) came on function in January 2005 on the 10th anniversary of the Kobe earthquake. It is placed in the city of Miki, to the north of Kobe and it is the largest shaking table in the world. The massive 6-DOF shaking table platform measures $20 \times 15 \mathrm{~m}$ and can accommodate a four-story building weighing 1200 tons. The maximum stroke is $\pm 1000 \mathrm{~mm}( \pm 500 \mathrm{~mm}$ in vertical direction), the maximum velocity is $\pm 2000 \mathrm{~mm} / \mathrm{s}( \pm 700 \mathrm{~mm} / \mathrm{s}$ in vertical direction) and the maximum acceleration is $1 \mathrm{~g}(1.5 \mathrm{~g}$ in vertical direction) in the frequency range of $0-50 \mathrm{~Hz}$.

\section{Major shaking tables in China}

Tongji University in Shanghai (Marazzi and Molina 2009a) is constructing the largest shaking table array in China. The system will consist of four tables that can be moved inside trenches to be positioned in different configurations. The tables will have 3 -DOF and will measure $4 \times 6 \mathrm{~m}$ each. The maximum stroke will be $\pm 500 \mathrm{~mm}$, the maximum velocity will be $\pm 1000 \mathrm{~mm} / \mathrm{s}$ and the maximum acceleration will be $1.5 \mathrm{~g}$ in the frequency range of $0-50 \mathrm{~Hz}$. The tables will have different payloads: two of them will support 30 ton specimens, and the other two tables will support 70 ton specimens.

\section{Major shaking tables in Korea}

The Korean government has launched the project of building 12 large scale testing facilities at the major universities in the country (Kim et al. 2008). These laboratories will be interconnected by using a high performance information network. In particular one of them will be a multi-platform seismic simulation facility with one $5 \times \mathrm{m}$ 2-DOF fixed shaking table and two moveable $3 \times 3 \mathrm{~m}$ 2-DOF shaking tables.

\section{Major shaking tables in Europe}

The main shaking table installations in Europe (Taucer and Franchioni 2005) are located in France (CEA), Italy (Eucentre) and Portugal (LNEC) (see also http://www.en.wikipedia.org/wiki/Earthquake_shaking_table) for a comprehensive and updated list of the shaking table installations in Europe and all around the word, even if the information reported therein must be checked and updated in agreement with the information given in the official website of each installation). Their capabilities are significantly lower than those of the major facilities either existing or under construction in the rest of the world. Azalee shaking table of CEA has six degrees of freedom, maximum stroke $\pm 125 \mathrm{~mm}$, payload 100 tons and maximum acceleration $\pm 1 \mathrm{~g}$. Eucentre shaking table has 1 degree of freedom, maximum stroke $\pm 500 \mathrm{~mm}$, maximum payload 70 tons and maximum acceleration $\pm 6 \mathrm{~g}$. LNEC shaking table has three degree of freedom, maximum stroke $\pm 290 \mathrm{~mm}$, maximum payload 40 tons and maximum acceleration $\pm 2 \mathrm{~g}( \pm 1 \mathrm{~g}$ in vertical direction). 
Table 2 Major reaction walls facilities in the word (Marazzi and Molina 2009b)

\section{Major reaction walls in USA}

The NEES Equipment Site at the Lehigh University (http://www.nees.lehigh.edu/) includes a strong floor that measures $31.1 \times 15.2 \mathrm{~m}$ in plan, and reaction walls up to $15.2 \mathrm{~m}$ in height. Anchor points are spaced on a $1.5 \mathrm{~m}$ grid along the floor and walls. The hydraulic equipment is capable of delivering a flow of $15001 / \mathrm{min}$ at a pressure of $20.7 \mathrm{MPa}$. The actuators have capacities comprised between 1.5 and $2 \mathrm{MN}$ and strokes of $\pm 0.5 \mathrm{~m}$. The NEES Equipment Site at the University of Illinois at Urbana-Champaign (http://nees.uiuc.edu/) has an L-shaped post-tensioned concrete strong wall of $15.2 \times 9.1 \times 8.5 \times 1.5 \mathrm{~m}$ (length $\times$ width $\times$ height $\times$ thickness, respectively) providing a reaction structure that enables testing of full scale. The laboratory is also equipped with Load and Boundary Condition Boxes (LBCBs), self-reacting assembly of actuators, swivel joints and control software capable of imposing any combination of six actions (forces and moments) and six deformations (displacements and rotations) to test specimens connected to its loading platform. The actuators have capacities from 0.5 to $3 \mathrm{MN}$ and strokes ranging between \pm 0.125 and $\pm 0.25 \mathrm{~m}$.

The NEES Equipment Site at the State University of New York at Buffalo (http://nees.buffalo.edu/) comprises in addition to the shaking table array a reaction wall and a strong floor. The reaction wall is $9 \mathrm{~m}$ height and $7 \mathrm{~m}$ long, with a strong floor with a surface of $12 \times 24=288 \mathrm{~m}^{2}$. In addition to the shaking tables' actuators, the laboratory is equipped with actuators having a force capacity comprised between 0.7 and $1 \mathrm{MN}$. Their stroke $\pm 0.15 \mathrm{~m}$.

The NEES Equipment Site at the University of California at Berkeley (http://nees.berkeley.edu/) comprises a reconfigurable Reaction Wall-Based Earthquake Simulation Facility. Twenty-four $3050 \times 2740 \times 760 \mathrm{~mm}$ hollow modular reinforced concrete wall units may be post-tensioned to the strong floor using 12 threaded rods with a prestressing force of $445 \mathrm{kN}$ per rod to build one or more reaction walls up to $13 \mathrm{~m}$ in height. The reaction wall's maximum shear force and bending moment are 1780 and $5420 \mathrm{~m} \mathrm{kN}$, respectively.

\section{Major reaction walls in Japan}

The Building Research Institute (BRI) (http://www.kenken.go.jp/english/) has a large structural laboratory with two strong floors and two reaction walls. The reaction floors $(20 \times 25 \mathrm{~m}$ and $15 \times 20 \mathrm{~m})$ are coupled with two $25 \mathrm{~m}$ high reaction walls crossed at right angles by another $15.5 \mathrm{~m}$ high wall. The shear force and bending moment capacities of the wall are $40 \mathrm{MN}$ and 720, respectively. Each one of two test floors can accommodate a building specimen of as much as $300 \mathrm{~m}^{2}$ floor area and $25 \mathrm{~m}$ height. Servo-controlled actuators have capacity of $1000 \mathrm{kN}$ in force and $\pm 500 \mathrm{~mm}$ in stroke.

\section{Major reaction walls in Taiwan}

The main seismic testing facility composed of a reaction wall and a strong floor is at the National Centre for Research on Earthquake Engineering (NCREE) (http://www.ce.ntu.edu.tw/eng/introduction/about.htm). The L-shaped reaction wall in this facility adopts the cell type design with stepwise arrangement of wall heights including 15,12, 9 and $6 \mathrm{~m}$ and the respective wall width of 15.5, 15.5,12 and $12 \mathrm{~m}$. There are 18 sets of static hydraulic actuators and six sets of dynamic hydraulic actuators with capacities comprised between 0.5 and $1 \mathrm{MN}$ and strokes ranging between \pm 0.25 and $0.5 \mathrm{~m}$.

\section{Major reaction walls in Europe}

The main reaction wall installation in Europe is the ELSA reaction wall located in Ispra (VA), Italy (http://elsa.jrc.ec.europa.eu/). The reaction wall is $16 \mathrm{~m}$ high and $20 \mathrm{~m}$ long, with two reaction platforms of pre-stressed cellular construction with a total surface of $760 \mathrm{~m}^{2}$ that allow for testing of real scale structural models on both sides of the wall. The laboratory is equipped with 20 actuators with capacities comprised between 0.5 and $3 \mathrm{MN}$ and strokes ranging between \pm 0.25 and $\pm 0.5 \mathrm{~m}$. The hydraulic equipment is capable of delivering a flow of $1500 \mathrm{l} / \mathrm{min}$. The reaction wall's maximum shear force and bending moment capacities are 20 and $200 \mathrm{MN} \mathrm{m}$, respectively; the strong floor bending moment capacity is $240 \mathrm{MNm}$.

large variety of structures and systems. In fact, such a facility is an indispensable tool to calibrate and validate new conceptual approaches in modelling and simulations developed for performance based analysis and design of new structures or retrofitting interventions of safe structures in Europe and even world wide. It will also contribute to increase world-wide the competitiveness of European science and industry. Therefore, the European commission 
has granted, within the 7th Framework Program, the EFAST project (design study of a European Facility for Advanced Seismic Testing). The main objective of EFAST is to determine the general characteristics of that new facility of European level and propose a preliminary design of it (http://www.efast.eknowrisk.eu/EFAST/).

The following presentation begins with a very short overview of testing methods in EE. Then, on the basis of the work done within EFAST, the European needs for seismic testing are discussed and the general characteristics and requirements for an advanced testing facility are presented.

\section{Testing methods}

In the following a brief overview of the main experimental techniques and their application field are given aiming at analyzing advantages and disadvantages in the perspective of the design of a new innovative multipurpose facility. Nevertheless the following apercu is not an exhaustive list of all existing experimental techniques. For instance, some methods which have been applied only rarely or are not sufficiently mature yet are not discussed (e.g. Diming et al. 1999).

\subsection{Shaking table}

Shaking table testing is one of the oldest and more frequently used experimental methods in earthquake engineering. The method is a direct simulation of the physical phenomenon since it imposes a base induced loading as do real earthquakes. Shaking table tests are real-time dynamic tests and they can deal with phenomena that cannot be accounted for by other testing methods. Their main advantages are that:

- They are more representative of real behaviour in case of rate-dependent constitutive laws.

- They can apply horizontal and vertical earthquake excitations. Rotational input is also possible if needed.

- They are very well suited to systems with distributed mass giving rise to distributed inertial forces (e.g. liquid storage tanks, out of plane bending of masonry walls, etc.).

- They are well suited for seismic qualification of sensitive equipment.

- They can account for dynamic coupling between horizontal excitation and vertical response (e.g. rocking and overturning of solids, dynamic variation of axial force due to cracking of reinforced concrete walls subjected to horizontal excitation).

As it is the case for all the testing methods, their drawbacks are often the other face of their advantages:

- Since the supporting and hydraulic system must have the capacity of carrying vertically the structure and supply the power corresponding to the earthquake input, relatively big specimens cannot be tested. Therefore, often, only a small part of the structure or a scaled model of it can be tested. In both cases questions may arise regarding the match between models and prototype.

- In the case of scaled models, similitude laws have to be used. Nevertheless, in some cases, the applied practical similitude law cannot satisfy the invariance of all the relevant dimensionless parameters associated to different physical phenomena. As an example, let us consider a model of a building on sliding bearings having a velocity dependent friction coefficient. If a gravity similitude is considered, in order to satisfy the ratio between 
gravity and earthquake induced forces, the model velocity will not fit the scaled velocity. This means that a discrepancy between actual and experimental sliding behaviour will occur. In general, scaling also cancels, partially, the reliability of the method regarding rate-dependent behaviour. Moreover, even in the case the theoretical similitude laws can be respected, the constitutive laws of some materials (mainly brittle materials) do change with the scale due to the so-called size effect.

- In general, for fast testing systems, such as shaking table and real-time hybrid testing, the control is by far less accurate than for quasi-static methods, such as the pseudodynamic (PsD) technique. In particular, spurious base motions, such as rocking, may be induced due to the admittance of the supporting system and/or the actuators because the control cannot fully compensate undesirable motions (Molina et al. 2008). Spurious motions also may occur due to the deformability of the table plate itself (Le Maoult et al. 2009).

\subsection{The pseudo-dynamic method}

The pseudo-dynamic (PsD) testing technique is based on a numerical integration of a discrete-DoF equation of motion containing a theoretical mass matrix and seismic-equivalent external loads, but with a physical model for the restoring forces. For every time-discrete state, the computed displacements are imposed to the physical model by means of actuators and the corresponding restoring forces are measured by load cells. The method is called PsD because the displacements are applied quasi-statically and, consequently, without the presence of physical inertial forces. The main advantages of the method are the following:

- Specimen dimensions can be, in general, larger than those of specimens on typical shaking tables. This is particularly true in the case of very slow pseudodynamic tests since, working quasi-statically, one can have large forces, accurate control and reduced hydraulic power at the same time. Therefore, many tests can be carried out without size reduction.

- Since there is no physical base input motion, the specimen can be put on a stiff foundation, thus avoiding spurious base motion.

- Since the experimental time is much longer than real time, the operator can stop the test in the case an undesirable behaviour is observed during the test. In general, due to the elongation of the time scale, control difficulties can be handled more easily than in real time tests.

- Specimen can be limited to a small substructure (the part that is difficult to model numerically) and the remaining restoring and inertial forces can be simulated numerically in the equation of motion. This technique is called substructuring and has been successfully implemented with the PsD method for many years for important real applications (Dermitzakis and Mahin 1986; Pegon and Pinto 2000; Pegon et al. 2008), while for shaking table and hybrid tests is still under development.

The main drawbacks are:

- The method is restricted to systems with inertial effects that can be modelled accurately with a small dimension lumped mass matrix (e.g. buildings with masses concentrated to the floors). It is not suited for distributed mass systems.

- Rate-dependent effects cannot be accounted for, unless they are not too strong and some compensation techniques are applicable (Palios et al. 2007).

- Even though vertical dynamic excitation can in theory be applied, it would require installing at least as many additional vertical actuators as vertical degrees of freedom. Therefore, to the authors' knowledge, because of this practical limitation, such tests have never been carried out. 
- Since forces are applied by a limited number of actuators, the state of stresses may be different from that of the prototype in the vicinity of the loading points. Therefore, special load-distributing attachments, inserted between the actuators and the specimen, may be needed to minimize local effects.

- The method cannot reproduce the dynamic coupling between horizontal excitation and dynamic vertical response.

It is worth noting that methods for real time pseudodynamic tests are receiving growing interest (Nakashima and Masaoka 1999). With real-time pseudodynamic tests, rate dependent effects are in principle correctly reproduced (if velocity is tracked satisfactorily). Nevertheless, these methods have to face problems, such as computation time and compensation of time delay which are common to all real-time control problems and in particular to real-time hybrid tests, discussed in the following subsection.

\subsection{Real time hybrid testing}

The idea of the PsD test can be extended to a more general category of tests called hybrid. In a hybrid test, by definition, a part of the force terms appearing in the equation of motion are experimentally measured, whereas the other part is numerically modelled. The PsD method described in the previous subsection is an example of hybrid test in which all the inertial forces are numerically simulated. On the other hand, regarding the restoring forces, sometimes some of the structural elements are in the physical model (experimental substructure), while some others are numerically simulated (numerical substructure). Depending on the rate of loading these tests may be either "real time" or "extended time scale" (fast or quasi-static) tests. The interest of hybrid methods in general is obvious since the "easy" or "known" part of the structure can be modelled numerically and the capacity of the experimental devices can be devoted exclusively to the "difficult" or "unknown" substructure. Pseudodynamic (hybrid extended time scale) substructuring tests have been successfully carried out on real applications as it is mentioned in the previous subsection. Real time substructuring methods appeared recently and for the time being only relatively simple tests are feasible. Actually many difficulties arise during this kind of tests. Among others one can mention problems related to (Marazzi and Molina 2009a; Ahmadizadeh et al. 2008; Blakeborough et al. 2001; Bonnet et al. 2008; Kim et al. 2008; Tu et al. 2010; Wu et al. 2007):

- The accuracy of the integration algorithms, in particular in the case of rate dependent behaviour. In fact in that case, the controlled variables of interest are not only the applied actuators displacement or force increments in a time step but also their rate.

- Time delay and response time of the actuators.

- Influence of measurement noise on the control action.

- Accurate control of very small relative displacements using large stroke actuators in the case the physical substructure is on a shaking table and the actuators applying the reactions of the numerical substructure are attached to the reaction wall.

- Realistic boundary conditions that are different from a simple force or displacement as, for instance, when a full distributor (displacements and rotations) or wrench (forces and torques) should be applied.

- Short required computation time implying that numerical substructures with only a few degrees of freedom can be considered since the computation must be done in real time. Alternatively, special computational techniques should be adopted to increase computational efficiency. 
Despite the aforementioned problems, as a strategic investment, the design of new testing facilities should anticipate future evolution and progress in that field, making this kind of testing more "common practice" in the future. Moreover it should be pointed out that progress in this field has a beneficial impact to "conventional" experimental techniques also which benefit from advances made in control, measurements etc.

\subsection{Geographically distributed testing}

A geographically distributed test is a particular case of hybrid test in which some of the substructures (experimental or numerical) coupled during the experiment are placed in different laboratories separated by a physical distance (Marazzi et al. 2010). The technological challenge for this testing technique is high since it requires, in addition to hybrid testing capabilities in the laboratories, not only performance in the hardware networking and protocols but also capabilities for collaboration in standards for communication and exchange of information. Considerable effort has been put in the research for the development of this type of testing in the recent years and some successful experiments have been performed, mostly using the PsD quasistatic approach due to the considerable distance among the involved laboratories (http://www.nees.unr.edu/aboutnees.html, http://www.series.upatras.gr/overview). Nevertheless, as it has been recognized by the experts attending the 1st EFAST Workshop (Marazzi and Molina 2009a), the main interest of this testing technique is the cooperation aspect among the laboratories. In fact, it is expected that the performances of this kind of testing will remain limited in the near future, mainly due to limitations related to the network communication speed. The proposed European facility should thus have the internal and networking capabilities for carrying out this type of test. Therefore it should have capabilities for hybrid testing, as mentioned above, and be endowed with the best available networking technology. Currently, a considerable collaborative work is carried out in this field, at a European level, in the framework of the research project SERIES (http://www.series.upatras.gr/ overview).

\section{Testing needs}

This section presents the needs for further experimental EE research in Europe. It is a brief summary of the discussions and conclusions of the 1st international EFAST workshop that assembled about 30 experts on earthquake engineering. It reflects also the results of an inquiry sent to three target groups of current or potential users of earthquake experimental facilities (Marazzi and Molina 2009c). The target groups include research laboratories, industry (mainly nuclear industry companies and institutions) and construction companies. Unavoidably, this presentation reflects also the personal point of view and professional experience of the authors. The needs inventory is split into different problem classes.

One common point to all classes of problems is that, in order to conduct a meaningful probability risk assessment, the actual available margins of structures have to be estimated. This holds for all structures but it is even more critical for structures of major importance (e.g. power generation facilities, hospitals etc.). To this end, tests with excitation level up to failure should be possible in future. Depending on the tested structure of interest (building, equipment or secondary structure), failure can be defined as loss of operational function, collapse or relevant significant damage or collapse. This implies that the new facility should have the capability to apply high intensity excitations (high acceleration, velocity and displacement) to models that will be representative of the prototype structures. 


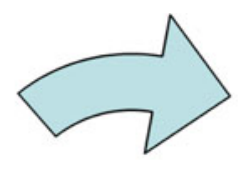

technolgies

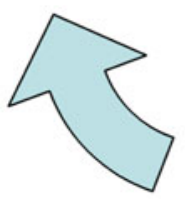

needs

Fig. 1 Interaction between testing technology-needs-methods

It is also worth mentioning that needs, testing technology and methods are tightly interconnected, as shown schematically in Fig. 1. An improvement of testing methods can suggest new type of tests and thus new needs. In a similar way, new needs result in research on new technologies which, on their turn, improve the capability and efficiency of testing methods.

\subsection{Objectives of seismic tests}

Generally, according to their main objectives, seismic test can be classified in one of the following three categories:

1. Qualification tests aiming at qualifying the seismic response of equipment or valuable goods. The scale must be necessary 1:1; because scaling effects must be completely avoided since the prototype has to be qualified. Tests of this kind are often required by regulations. They are necessary when it is extremely difficult to build an analytical model (e.g. electric cabinets in power generation facilities) and when a yes or no answer is needed or is the only possible realistic answer.

2. Demonstration tests motivated by disseminations purposes or by strategic reasons such as to convince policy makers. Usually, the tested models are at the biggest possible scale.

3. Research and development oriented tests which are necessary for one or more of the following purposes:

- to obtain a better physical insight for both local and global structural behaviour;

- to validate or calibrate the available numerical models, the modelling techniques and the level of inherent approximation;

- to propose or validate codes recommendations and guidelines.

All three categories may need comparable capacity of the experimental facility. For instance, the qualification of heavy equipment at scale 1:1 may need a force capacity comparable to that of a frame building model at a smaller scale. Consequently, high performance is needed in all cases.

Both categories 1 and 3 need a high quality accurate control software and hardware to avoid considerable discrepancies between target motion and achieved motion. In addition, for category 3, accurate, reliable and advanced measurement techniques are necessary to enable a satisfactory exploration of the experimental results. 


\subsection{New buildings}

Despite the considerable progress made in the design and analysis of new buildings as well as the improvement of regulations, further research is necessary in several fields. An overview of research needs for normative purposes is presented in Pinto et al. (2007). Among others one can mention the following topics:

\subsubsection{In-plan irregular buildings}

Research is necessary to establish how to measure the static or natural eccentricity of a building structure, and how it is affected by the changes in strength distribution. It is also important to set the grounds to move from a torsional failure criterion based on ductility ratio demands to a more rational one based on member absolute deformations, such as drifts.

\subsubsection{Buildings with flat slab systems}

Due to the lack of sufficient available data, current regulations impose, conservatively, low behaviour factor for flat slab systems which are very common in several European countries. Further experimental research is needed in this field to increase their ductility class.

\subsubsection{Precast, prestressed concrete elements and systems}

Precast elements assemblies should be further assessed to properly understand their behaviour under seismic loads. Effective models for both simulation and design of precast structures are also needed, especially regarding joints and foundations. Prestressed technology for post tensioning of concrete and lamellar wood are now emerging. Therefore a reliable experimental evaluation of their effective behaviour and of the overall safety of the proposed conceptual design and detailing is needed.

Seismic response of masonry buildings and buildings with masonry infills need to be further investigated. In particular there are very few tests carried out on masonry structures with more that two storeys. The pseudodynamic method can give useful insight into the response of such structures but, because of the distributed mass of walls and infills, shaking table tests would be also relevant. Obviously, dynamic tests on shaking table are meaningful if the model scale is not too small. A considerable number of tests should be conducted because of the variability of construction techniques and materials. The out of plane behaviour of masonry structures and rules for "simple buildings" should be assessed. A further insight into the role of non-structural masonry infills' is also necessary. It is worth noting that Eurocodes (http://www.eurocodes.jrc.ec.europa.eu/) do not include any provision that accounts, explicitly for the infills contribution to the building capacity. In fact, regarding new buildings EN 1998-1:2004 considers infills qualitatively as a second line of defence but there is no guidance enabling the assessment of the actual building capacity. The lack of such guidance for existing buildings in EN 1998-3:2005 is even more critical, since the contribution of infills to the capacity of the building may be substantial.

All the aforementioned aspects deal with quite complex phenomena which cannot be investigated reliably with small scale models. Therefore, a high capacity experimental facility is needed in order to carry out tests at the biggest possible scale. 


\subsection{Infrastructures}

There is a strong need for further experimental and analytical studies on the seismic response of bridges and viaducts with special attention to the three-dimensional character of their response, the constraint and isolation devices, the flexibility of their foundations and the actual behaviour of the most critical elements. Soil-structure interaction and non-synchronous ground motion must also be investigated further. The aforementioned topics are of interest not only for new bridges, but also for existing bridges due to degradation of their properties (ageing) and/or higher required performance level (increased traffic, increased seismicity etc.). Even though all these aspects cannot be completely studied experimentally by means of full scale models, a new facility should have the possibility to investigate some of the aforementioned questions as, for instance, asynchronous base motion of reduced scale models. This implies that a multiple support excitation is necessary.

\subsection{Retrofitting}

Repairing and/or strengthening of existing structures is a major concern of earthquake engineering during the last decades. In fact there is a plethora of new techniques and materials (e.g. fibber reinforced polymer materials, structural glass, wood-based composites etc.) which are added to the already long list of more traditional techniques. The combination of different materials and the uncertainty on the characteristics of the existing structure makes the retrofitting a complicated problem that cannot be treated only analytically. The aforementioned aspects are of major importance in the case of retrofitting of structures related to cultural heritage. Presently, there are no Eurocodes on cultural heritage interventions, but it is commonly accepted that interventions should be low intrusive and take into account long term consequences. The wide variety of these constructions makes very difficult to write a dedicated code. On the contrary, each structure is unique and need a specific study.

Therefore a further experimental research is necessary in the aforementioned issues. Testing may be required to assess either the original or the retrofitted structure or both. Reliable design codes for new structures have entered into force in Europe only in the last decades and the number of non-seismically-designed structures is larger than in USA or Japan (Marazzi et al. 2000). To be representative of the actual global and local behaviour of real retrofitted structures the models should be tested in laboratory at the biggest possible scale (http://www. ectp.org/default.asp).

\subsection{Aseismic devices}

Aseismic devices, like isolation bearings, have to be systematically tested for qualification purposes. In Europe, currently, the less demanding tests are usually carried out either by the manufacturers themselves or in the existing facilities. Tests on large dimension bearings were not very common in the past but nowadays big isolators are used more frequently in several projects. These qualification tests are done with dedicated experimental set-ups as for instance those at the University of San Diego, US, or at EUCENTRE in Pavia, Italy. However, even the EUCENTRE testing machine, which is the biggest in Europe, cannot test very big bearings. The demand for tests on anti-seismic devices will tend to increase with entering into force of the European Standard EN 15129 and the increase of the number of structures incorporating such devices. Therefore, Europe should be endowed with the capacity for doing also large scale tests in the future. 
In addition, the influence of these devices on the structure response as well as on sensitive equipment (e.g. equipment of nuclear plants) or secondary structures (e.g valuable objects like statues in museums etc.) has to be studied further. This implies dynamic shaking table tests. Shaking tables in this case should have a large displacement capacity in order to reproduce correctly earthquake records having significant low frequency content.

\subsection{Equipment and components}

The proper operation of industrial and power generation plants depends to a considerable extent on the capacity of sensitive equipment to respect the required performance criteria under severe earthquake events. The same holds also for other buildings of major importance as, for instance, hospitals, or even museums where the integrity of statues or other valuable objects is of paramount importance. Therefore the behaviour of secondary structures has to be studied further. To this end, numerical and experimental research projects and/or qualification tests have to be conducted. This implies that the facility should be able to reproduce the adequate floor signal. Dynamic floor amplification may be considerable and components must be tested under high acceleration (of about $4 \mathrm{~g}$ or more) in the frequency range form 0.1 to $50 \mathrm{~Hz}$. For equipment in seismically isolated buildings, as already mentioned, a large displacement capacity shaking table is necessary to reproduce the adequate floor input motion.

\subsection{Soil-structure interaction}

Soil-Structure Interaction (SSI) is a common issue to the majority of EE problems. The two major aspects of soil structure interaction are energy radiation and possible nonlinear behaviour of the soil or of the soil-structure interface (nonlinear soil deformations, sliding and or uplift of the foundation etc.). The effects of SSI on the structure response are a major source of uncertainty. Consideration of the structure, of its foundations and of the soil as a system may lead to alternative cost-effective seismic design concepts that will enable-under certain conditions - concentration of nonlinearity and energy dissipation in the soil or in the foundation. It may also change the ductility demand in the superstructure, leading to a modification of the recommended values of the behaviour factor.

Unfortunately, there are not satisfactory experimental methods to deal with SSI. One method is on site measures of responses to real earthquakes or to explosions or even ambient noise (Tang et al. 1990, 1991; Morisita et al. 1993). Another method is testing of very small scale models in laboratory centrifugal machines. However, though centrifugal tests may be well suited for studying the soil behaviour, the structure scale is so small that it is no more representative of the prototype.

Tests on shaking tables are not very frequent as it is extremely difficult to carry out tests of models in a meaningful scale. In fact, tests should be as close as possible to real scale in order to avoid scaling effects, but technological problems still prevent from a complete satisfaction of this requirement. Efforts to deal with energy radiation by means of shear boxes, having adequate passive or active lateral boundary conditions, do not give a satisfactory solution because the spurious wave reflexions on the lateral boundaries cannot be completed eliminated. Moreover, wave reflexions occur at the table plate also. However, in the case of local nonlinear soil and/or soil-structure interface behaviour, nonlinearity may dominate the response, putting energy radiation in a second plane. Soil structure interaction earthquake tests on shaking tables could mainly deal with this class of problems where the distance of boundaries (lateral boundaries and table surface) from the foundation need not to be very big. 
However, even in this case, several problems persist. In fact, full scale models are not feasible because of the huge soil dimensions and weight them would imply. On the other hand, in the case of scale models, similitude law cannot satisfy static soil stresses. The smallest meaningful scale would be of about 1:4 (Marazzi and Molina 2009a). It is worth noting that even this scale results in very heavy models even for simple prototype structures. For instance, let us consider that the prototype structure is a bridge pier $12 \mathrm{~m}$ high on a foundation $7 \mathrm{~m}$ wide supporting a deck with a weight of 1000 tons. A reasonable 1:4 scale specimen would consist of a soil container $3 \mathrm{~m}$ high having horizontal dimensions of about $7 \times 7 \mathrm{~m}$. The total model weight would be of about $5,000 \mathrm{kN}$.

The necessary dimensions and weight for representative tests imply that only very simple, elementary configurations can be tested on shaking tables.

A bigger scale could be envisaged using the PsD method with the test superstructure sited on, or embedded in a soil contained in a pit surrounded by the soil of the facility. Two major drawbacks of this method are the difficulty of determining accurately the inertial loading to be considered and the rate dependent behaviour of many SSI problems which does not comply with the PsD technique (Sect. 2.2). However, despite the aforementioned drawbacks and given that there is not an ideal SSI testing method, the suggested method could be used on occasion as an alternative method.

For all methods, comparison with numerical simulations is of a paramount importance in order to develop and validate accurate numerical models that could allow us to investigate configurations much more complicated than that which can be physically tested

\section{Characteristics of a new European world class facility}

As already mentioned in the introduction, one of the reasons which motivated the reflexion on a new seismic testing facility of a European level is that there is a risk for Europe to suffer a considerable delay with respect to Asian countries and the USA in EE research based on shaking-table testing. In fact there is an emergence of high performance facilities in those countries. Regarding pseudodynamic testing, the ELSA laboratory of the JRC of the EC in Italy (http://www.elsa.jrc.ec.europa.eu/), with its reaction wall $16 \mathrm{~m}$ high and $20 \mathrm{~m}$ long is one of the main seismic testing facilities in the world The situation is different for European shaking tables facilities, having considerably lower performances than that of the major shaking tables laboratories in the world. Therefore it is proposed that the new facility should be, mainly, a shaking table facility. It should allow the scientific community to carry out tests that will meet as close as possible the needs presented in the previous section. In addition, the new facility should comply as far as possible with the requirements of flexibility, adaptability and operational ease.

\subsection{Capacity and lay-out of the experimental facility}

Table 3 shows some indicative performance parameters for different classes of tests. The given numbers are reasonable rough estimates as a trade-off between needed performance and cost. Obviously it is not feasible, either for technological or financial reasons, to build a facility so big that everything could be tested therein. The objective is to propose a design that will enable to carry out meaningful tests using conventional and/or more recent techniques and technology which have already demonstrated their efficacy and reliability. Actually, even though research on feasibility of advanced experimental techniques, like real-time hybrid testing, is an objective of EFAST, EFAST is mainly a design study project. It does not aim 
Table 3 Performance demand for possible classes of tests

\begin{tabular}{llll}
\hline & $\begin{array}{l}\text { Soil-structure } \\
\text { interaction }\end{array}$ & $\begin{array}{l}\text { Tests on civil engineering } \\
\text { structures }\end{array}$ & $\begin{array}{l}\text { Secondary structures } \\
\text { or equipment }\end{array}$ \\
\hline Height of specimen & $6 \mathrm{~m}$ & $15 \mathrm{~m}$ & $10 \mathrm{~m}$ \\
Mass of specimen & 500 tons & 200 tons & $1-100$ tons \\
Number of directions & 1 & $1-3$ & $1-6$ \\
Displacement & $\pm 1 \mathrm{~m}$ & $\pm 1 \mathrm{~m}$ & $\pm 1 \mathrm{~m}$ \\
Velocity & $\pm 2 \mathrm{~m} / \mathrm{s}$ & $\pm 2 \mathrm{~m} / \mathrm{s}$ & $\pm 2 \mathrm{~m} / \mathrm{s}$ \\
Acceleration & $\pm 1.5 \mathrm{~g}$ & $\pm 2 \mathrm{~g}$ & $\pm 2 \mathrm{~g}(100$ tons $)$ \\
& & $0-50 \mathrm{~Hz}$ & $\pm 6-7 \mathrm{~g}(10$ tons $)$ \\
Frequency range: & $0.2-50 \mathrm{~Hz}$ & & $0-100 \mathrm{~Hz}$ \\
\hline
\end{tabular}

at investigating and developing new revolutionary experimental techniques which are not consolidated yet.

The acceleration values in Table 3, may seem to be unrealistically high. However, it is worth noting that (a) several records of real earthquakes revealed very high acceleration values (e.g. $0.98 \mathrm{~g}$ Northridge earthquake 1994, $0.85 \mathrm{~g}$ Kobe 1995) (b) in the case of scale models, if a velocity similitude is considered, the table acceleration should be multiplied by the inverse of the scale ratio i.e. table acceleration will be higher than ground acceleration of the prototype and (c) the values in Table 3 are conventional acceleration values corresponding to a rigid specimen. Consideration of the dynamic amplification of the specimen results in a higher demand of force capacity which is equivalent to a higher demand of conventional acceleration capacity. For instance, even the middle spectral amplification given by codes (of about 2.5 times the ground acceleration, for 5\% damping) will result in table accelerations of about $0.9 \mathrm{~g}$ at the full payload capacity. In the case of SSI tests, the major part of the mass on the table is due to the weight of the soil itself and its container which will have, in general, a weak dynamic amplification. Therefore, in that case the required shaking table acceleration could be smaller. Regarding secondary structures and equipment, because of the amplification of the shaking motion at the floor level, floor accelerations to reproduce on the table may be much higher than ground accelerations.

Velocity values are also in agreement with actual recorded velocities (e.g. $1.4 \mathrm{~m} / \mathrm{s}$ Northridge earthquake 1994, $1.5 \mathrm{~m} / \mathrm{s}$ Kobe 1995). High displacement values are also necessary for the shaking table motion to be representative of strong, low frequency ground motions or of floor motions of low frequency buildings (in the case of secondary structures or equipment tests).

As a first step towards the design of a future experimental facility of European interest, the schematic lay-out in Fig. 2 is proposed. As already mentioned, the proposed lay-out is the result of iterations between performance needs and cost. It is based on a preliminary cost estimate which is not communicated here since it is still under further investigation. In fact, a reliable cost estimate should include several aspects such as construction, linking to infrastructures, software, handling, operation, maintenance and risk assessment. This task is currently under progress. The laboratory will consist mainly of:

1. two 6 DOF $6 \times 6 \mathrm{~m}$ shaking tables. The payload of each table would be of about 100 tons. The tables can be positioned in any place within the trench. They will be able to operate independently or be linked and operate as a single table. Obviously a higher number of tables, possibly in different trenches, would enable testing more complex configurations 


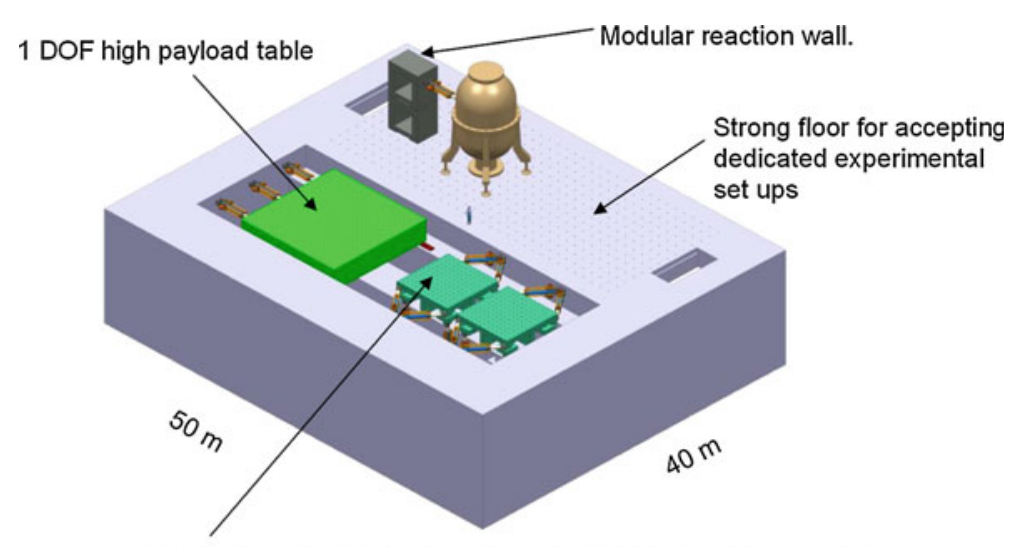

High performance 6 DOF shaking tables linked or independent

Fig. 2 Schematic lay-out of a new European level facility

(see Tongij University in Marazzi and Molina 2009a). However as already mentioned, the proposed facility is a trade-off between performance-capacity and cost, that is why only two tables are proposed;

2. one $1 \mathrm{DOF}$ (horizontal) shaking table with high payload of about 500 tons. This shaking table will be intended for heavy specimen and in particular for SSI tests like the one described in Sect. 3.7;

3. a big strong floor area where dedicated experimental set-ups and testing machines could be flexibly mounted on;

4. a modular reaction wall allowing for real-time hybrid testing possibly combining shaking tables and actuators attached on the wall;

5. a hydraulic system composed of piping, actuators, pumps and accumulators with a capacity close to the performance criteria given in Table 3;

6. a high capacity crane bridge spanning the whole width of the working area and an outdoor area devoted to the construction of specimens.

If necessary, the maximum payload of the two $6 \mathrm{DOF}$ tables could be increased with minor modifications of the supporting system. However, unless the actuators' capacity increases, this will be done at the price of a smaller maximum acceleration at full payload.

In addition adequate control hardware and software has to be specified, purchased or developed to obtain satisfactory control of the tables, dedicated set-ups and additional actuators in the case of hybrid testing.

\subsection{Numerical facility}

A strong interaction between the aforementioned "purely experimental" facility and a numerical high computational capability facility, on site or remote, is necessary. Actually, high performance and accuracy numerical simulation is necessary not only for advanced experimental methods, like real-time substructuring involving complex numerical substructures, but also for conventional tests. Being able to quickly obtain accurate results of predictive analyses before testing and interpretation analyses after testing is of a paramount importance for successful testing of models with complex behaviour. Predictive analyses are necessary to define the whole testing configuration (model geometry, boundary conditions, properties, input characteristics, measurement technology, sensor locations and calibration etc.). From 
the experimental point of view, interpretation analyses may be useful for the detection of problems or unexpected response that occurred during the test (e.g. unsatisfactory behaviour of sensors, actual boundary conditions different from that considered etc.). This aspect is of particular importance in the case of series of tests where fast numerical interpretation analysis can be used as a tool of quality control between two successive tests.

\subsection{Sensors, data processing and structural monitoring}

Measurements techniques and systems evolve very rapidly. These new devices enable not only better quality measurements, but also new type of measurements, as for example low invasive or no contact measurements etc.

For instance, rapid advances in optical fibers, optical sensors, wireless communication, Micro-Electro Mechanical Systems (MEMS) and information technology-software frameworks, databases, visualization, Internet/Grid computations-have the potential to significantly impact the way complex structural systems are tested in large-scale facilities. Along these lines dense arrays of sensors are envisioned for large civil engineering structures/infrastructures, including foundations and the soil. To cope with the large amount of data generated by a measuring system, on-board processing at the sensor itself allows a part of the computation to take place locally by the sensor's embedded microprocessor. Such an approach leads to adaptable sensor topologies and smart sensors, with self-diagnosis and self-calibration capabilities, reducing the amount of information that needs to be transmitted over the network. Remarkable improvements are envisaged also from remote measurements when direct contact with the structure should be avoided, e.g., for safety reasons or in emergency situations, or when installation of conventional instruments is impractical for technical or economic reasons. The adoption of new kind of sensors leads to advances in data processing and analyzing techniques. Structural monitoring methods, including system identification techniques, damage assessment and model updating tools, are evolving very rapidly and will play a major role in the near future.

The new testing facility should be directly involved into these development processes and have the capabilities and human resources for studying and testing the new developed techniques and sensors.

\subsection{Database and telepresence}

Efficient better dissemination and use of experimental results should be a requirement for a new facility. An easy and fast access to data coming from experimental testing campaigns will foster the impact of earthquake engineering research on practice, innovation and earthquake risk mitigation and will provide a broad and solid base for the calibration of numerical models. A web portal should give user-friendly access to the data contained into the database. The database and the user interface should be integrated into the European scientific experimental database network. The new testing facility should provide remote users access to the data during the experiment itself (on-line access), virtual access to the equipment and enable collaborative decision making regarding the testing activities (telepresence). This is also essential for tests involving concurrent use of geographically distributed platforms (distributed testing). 


\section{Conclusions}

This paper presents a synthesis of the work done in the framework of the European project EFAST to define the general characteristics of a new European world class facility for seismic testing of structures (Marazzi and Molina 2009b). The need for such a facility comes mainly from the increase, in the last decades, of the needs for further experimental research with big scale models and strong input shaking motions. This is also reflected in the increasing number of new high performance shaking-table facilities world-wide that would soon restrict Europe to a secondary role in the field of EE if there is no reaction.

With the ELSA laboratory of the Joint Research Centre of the European Commission, Europe is equipped with a world class facility for pseudodynamic testing. However, this is not the case for shaking table facilities whose performances did not follow the evolution that took or is taking place in foreign countries. Therefore, it is proposed that the future facility should be a new generation dynamic testing facility. It will be composed, mainly, of high performance shaking tables and a large strong floor where dedicated experimental set-ups could be mounted on. In addition to the capacity for testing relatively big models under severe shaking motions, the new facility should meet, as far as possible, the requirements of flexibility and operational ease. It should also enable hybrid real-time testing, for research purposes in the near future and for purposes of practical interest in the future. Provision should also be made for the coupling of this facility with a high computational capacity numerical facility. For the European community to fully benefit from the future facility networking between the new laboratory and existing facilities should be developed.

A schematic lay-out of the facility is proposed. The main underlying philosophy is to make a significant progress with respect to existing European facilities but with a reasonable cost and using techniques and technology that have already demonstrated their efficacy and reliability. This proposal is under further investigation to define more precisely the dimensions, the preliminary design of the various components (reaction mass, hydraulic system, tables' plates, modular reaction wall, network connections etc) and estimate cost. In addition, other complementary aspects, necessary for successful experiments, are under study, such as, for instance, measurement techniques and technology and control issues.

Acknowledgments The work presented in this paper has been carried out in the framework of the European project EFAST (grant agreement no: 212109). This financial support is gratefully acknowledged by the authors. The authors would like to thank also all their partners of the EFAST project and in particular Dr. Javier Molina and Dr. Pierre Pegon for their useful remarks and suggestions.

\section{References}

Ahmadizadeh M, Mosqueda G, Reinhorn AM (2008) Compensation of actuator delay and dynamics for realtime hybrid structural simulation. Earth Engrg Str Dyn 37:21-42

Blakeborough A, Williams MS, Darby AP, Williams DM (2001) The development of rel-time substructure testing. Philos Trans R Soc London A 359:1869-1891

Bonnet PA, Williams MS, Blakeborough A (2008) Evaluation of numerical time-integration schemes for realtime hybrid testing. Earth Engrg Str Dyn 37:1467-1490

Dermitzakis SN, Mahin SA (1986) Development of substructuring techniques for on-line computer controlled seismic performance testing. UCB/EERC-85/04, Earthquake Engineering Research Center, University of California at Berkeley

Diming J, Shield C, French C, Bailey F, Clark A (1999) Effective force testing: a method of seismic simulation for structural testing. Str Engrg 125(9):1028-1037 
Kim CY, Park YS, Kim JK (2008) Hybrid testing facilities in Korea. In: Saouma VE, Sivaselvan MV (eds) Hybrid simulation; theory, implementation and applications. Taylor \& Francis/Balkema Publishers, London, UK, pp 91-97; ISBN 978-0-415-46568-7

Le Maoult A, Bairrao R, Queval JC (2009) Dynamic interaction between the shaking table and the specimen during earthquake tests. 20 SMIRT, 9-14 Aug, Espoo, Finland

Marazzi F, Magonette G, Anthoine A, Pinto A, Tirelli D, Pegon P, Renda V, Bono F, Molina FJ (2000) The role of ELSA laboratory in the field of cultural heritage protection. "Quarry-Laboratory- Monument" International Congress-PAVIA 2000, Pavia, Italy, 26-30 Sept

Marazzi F, Molina FJ (2009a) 1st EFAST workshop_challenges, needs and open questions, EUR 23822 EN. Luxembourg: Publications Office of the European Union. JRC5 51632. http://www.elsa.jrc.ec.europa. eu/list_pub.php?id=195\&year=2009

Marazzi F, Molina FJ (2009b) Preliminary report to ESFRI roadmap for the new research infrastructure EFAST. EUR 24007 EN. Publications Office of the European Union, Luxembourg. JRC 54505. http://www.elsa. jrc.ec.europa.eu/list_pub.php?id=195\&year=2009

Marazzi F, Molina FJ (2009c) EFAST inquiry. EUR 23998 EN. Publications Office of the European Union, Luxembourg. JRC 54178. http://www.elsa.jrc.ec.europa.eu/publications/JRC54178.pdf

Marazzi F, Molina FJ, Pegon P, Politopoulos I, Casarotti C, Pavese A, Le Maoult A, Atanasiu G, Nguyen V, Dorka U (2010) 1st year EFAST annual report. EUR 24354 EN. Publications Office of the European Union, Luxembourg. JRC 57809. http://www.elsa.jrc.ec.europa.eu/list_pub.php?id=355\&project=19

Molina FJ, Magonette G, Viaccoz B, Geradin M (2008) Apparent damping induced by spurious pitching in shaking-table testing. Earth Engrg Str Dyn 37:103-119

Morisita H, Tanaka H, Nakamura N, Kobayashi T, Kan S, Yamaya H, Tang HT (1993) Forced vibration test of the Hualien large scale SSI model. 12th SMiRT, vol. K, Stuttgart, Germany

Nakashima M, Masaoka N (1999) Real-time on-line test for MDOF systems. Earth Engrg Str Dyn 28:393-420

Palios X, Molina J, Bousias S, Strepelias E, Fardis M (2007) Sub-structured pseudodynamic testing of ratedependent bridge isolation devices. In: 2 nd international conference on advances in experimental structural engineering, Shanghai 4-6 Dec 1:262-269

Pegon P, Pinto AV (2000) Pseudo-dynamic testing with substructuring at the ELSA laboratory. Earth Engrg Str Dyn 29:905-925

Pegon P, Molina FJ, Magonette G (2008) Continuous pseudo-dynamic testing at ELSA. In: Saouma VE, Sivaselvan MV (eds) Hybrid simulation; theory, implementation and applications, Taylor \& Francis/Balkema Publishers, London, UK, pp 79-88; ISBN 978-0-415-46568-7

Pinto A, Taucer F, Dimova S (2007) Pre-normative research needs to achieve improved design guidelines for seismic protection in the EU. EUR 22858 EN. Luxembourg: Publications Office of the European Union. JRC 007741. http://elsa.jrc.ec.europa.eu/publications/JRC37741.pdf

Tang HT, Tang YK, Stepp JC (1990) Lotung large-scale seismic experiment and soil-structure method validation. Nucl Eng Des 123:297-412

Tang HT, Stepp JC, Cheng YH, Yeh YS, Nishi K, Iwatate T, Kokusho T, Morishita H, Gantenbein F, Touret JP, Sollogoub P, Graves H, Costello J (1991) The Hualien large scale seismic test for soil-structure interaction research. 11th SMiRT. vol. K. Tokyo, Japan

Taucer F, Franchioni G (2005) Directory of European facilities for seismic and dynamic tests in support of industry. CASCADE Series Report No. 6, LNEC, Lisbon, Portugal, ISBN 972-49-1970-6

Tu JY, Lin PY, Stoten DP, Li G (2010) Testing of dynamically substructured, base-isolated systems using adaptive control techniques. Earth Engrg Str Dyn 39:661-681

United Nations Development Programme (2006) Reducing Disaster Risk

University of Grenoble (2005) The SESAME Project. Site EffectS assessment using AMbient Excitations. http://sesame-fp5.obs.ujf-grenoble.fr/index.htm

Wenzel H (prepared by) (2007) European Strategic Research Agenda, "Earthquake engineering-vision-strategic research agenda_roadmap for implementation", European Association for Earthquake Engineering www.eaee.boun.edu.tr/earthquake-research-agenda-V9-August_Part\%2012.pdf

Wu B, Wang Q, Shing PB, Ouet J (2007) Equivalent force control method for generalized real-time substructure testing with implicit integration. Earth Engrg Str Dyn 36:1127-1149 